ARCHIVO ESPAÑOL DE ARTE, LXXXI, 324

OCTUBRE-DICIEMBRE 2008, pp. 379-394

ISSN: 0004-0428

\title{
SEBASTIÁN DE BENAVENTE Y LA CAPILLA DE SAN DIEGO DE ALCALÁ
}

\author{
POR \\ JUAN MARÍA CRUZ YÁBAR \\ Conservador de Museos Estatales
}

La correcta interpretación de los documentos relativos a la capilla de San Diego en el convento de Santa María de Jesús de Alcalá de Henares demuestra que el maestro arquitecto Sebastián de Benavente tuvo un papel fundamental en su invención y realización, incluido el retablo mayor. Consideramos suyo el dibujo de colección particular florentina hasta ahora atribuido a Alonso Cano, lo que defendemos por razones documentales y estilísticas.

Palabras clave: Capilla de San Diego de Alcalá; Retablos; Sebastián de Benavente; Alonso Cano.

The correct interpretation of the documents concerning the chapel of San Diego in the convent of Santa Maria de Jesús in Alcalá de Henares demonstrates that the master-architect Sebastián de Benavente played a fundamental role in its invention and realization, including the main altarpiece. For both documental and stylistic reasons, the author attributes to Benavente the drawing from a Florentine private collection until now attributed to Alonso Cano.

Key words: San Diego de Alcala's chapel; Altarpieces; Sebastián de Benavente; Alonso Cano.

La capilla de San Diego en el convento franciscano de Santa María de Jesús de Alcalá de Henares ha despertado el interés de los historiadores en los últimos años por la calidad de los artífices que participaron en ella y la importancia del significado de la obra. Sólo se había identificado a los autores de los cuadros de los retablos laterales, Cano y Zurbarán ${ }^{1}$, el pintor de la media naranja y sus pechinas, Gregorio de Utande ${ }^{2}$, y el artífice de la urna de plata del Santo, el

\footnotetext{
${ }^{1}$ Palomino (El museo pictórico y escala óptica, Madrid, 1724, Aguilar, 1947, p. 987) señaló que San Francisco y San Antonio eran de Alonso Cano. El Inventario del Museo de la Trinidad de 1854 (Museo del Prado. Inventario general de pinturas. II, Madrid, Espasa Calpe, 1991, n. ${ }^{\circ}$ 300, 303, 314 y 317) identificó los cuatro como Zurbarán. ToRmo (Las iglesias del antiguo Madrid, Madrid, 1927, p. 95) fue el primero en señalar la doble autoría.

2 NúÑEZ, L. M., "Contrato hecho entre el pintor Gregorio de Utande y la comunidad de San Diego de Alcalá", Archivo Ibero Americano, 5 (1916), pp. 465-466.
} 
platero Rafael González ${ }^{3}$, antes de que Pérez Sánchez desvelara en 1988 el nombre de muchos otros de los que intervinieron en la remodelación de la capilla tras haberle comunicado Agulló sus descubrimientos ${ }^{4}$. Esta investigadora ha publicado por fin un extracto de los documentos de la obra de la capilla junto con el estudio de los mismos. Analiza los contratos, en especial el del retablo mayor celebrado entre el maestro arquitecto Sebastián de Benavente y el procurador de la obra, que tiene fecha de 29 de abril de 1658. Afirma al respecto: "El documento es de extraordinario interés porque viene a confirmar que Alonso Cano fue el tracista del retablo que enmarcaría la urna de San Diego y que las modificaciones introducidas por Benavente y los franciscanos hacen referencia al precioso dibujo del granadino para el altar mayor de la capilla de Alcalá" Se refiere al dibujo de colección particular florentina publicado por Pérez Sánchez en 1986 con atribución a $\mathrm{Cano}^{6}$ (fig. 1). Ciertamente, no es imposible por razones cronológicas que Cano pudiera trazar el retablo de San Diego. Pero la lectura de los documentos referidos a la capilla y el conocimiento de la obra de Sebastián de Benavente nos sugiere una hipótesis diferente.

En un punto coincidimos plenamente con Agulló y es que el dibujo atribuido a Cano corresponde - con las precisiones introducidas en el citado contrato de 29 de abril de 1658 firmado con Benavente- con lo que se ejecutó en la capilla complutense. Este contrato incluye aclaraciones y alguna modificación sobre una traza previa que era el dibujo hasta ahora atribuido a Cano. Así, se elige para su ejecución el intercolumnio del lado del evangelio, que se describe con exactitud y coincide con el del dibujo, se seleccionan adornos que se pueden reconocer con facilidad, se detallan elementos no visibles por la frontalidad - pilastra que vuelve hacia el interior del camarín, florones en la parte inferior del arquitrabe- y se sustituyen los dos niños de las enjutas del remate por escudos de armas reales que en el dibujo figuraban situados en el zócalo. Sólo hay dos puntos en que se produce innovación. Se adicionan dos gradas o un zócalo en la parte donde se ha de asentar la custodia -lo que sería necesario por la nueva traza de ésta- y se reforma la disposición de las piezas del coronamiento: "la tarja que muestra encima del cuadro del sobrecuerpo a de benir ciñendo debajo del plafón que hace el frontispicio y no se a de hacer la piedra que muestra la traça porque a de levantar el lienço más alto conforme está hecha la pintura"; esta "pintura" es interpretada por Agulló como el lienzo superior, pero entendemos que está aludiendo al propio dibujo de la traza, donde Benavente habría señalado la modificación de algún modo; el cuadro superior se había de hacer más grande o poner más alto, para lo que se suprime el recuadro superior con orejetas que lo tapaba en parte y la gran tarja carnosa superpuesta se desplaza hacia arriba, adentrándose en el plano inferior de la cornisa -el plafón- que servía de remate. Las alteraciones respecto del primer proyecto, como se ve, fueron mínimas, lo que justifica que no se hiciera un segundo dibujo. La custodia, en cambio, mereció una traza especial porque los cambios serían importantes.

No es un obstáculo que en el contrato con Benavente se indique que la traza quedaba firmada y que el dibujo conservado no tenga firmas, como tampoco que no tenga rastros de la modificación del cuerpo superior. Es normal que el maestro se quedara una copia del proyecto mientras otra se firmaba y se entregaba a la otra parte. El dibujo florentino sería así la copia de Benavente.

\footnotetext{
${ }^{3}$ Cruz Valdovinos, J. M., "Platería", en Historia de las artes aplicadas e industriales en España, Madrid (Cátedra), 1982, p. 115. "Rafael González... en 1658 hizo la urna de San Diego de Alcalá (Magistral) en forma de paralelepípedo...”.

${ }^{4}$ Pérez SÁnchez, A. E., “Capilla de San Diego, en el convento franciscano de Alcalá de Henares”, en Zurbarán, Madrid (Ministerio de Cultura-BBV) 1998, pp. 327-335.

5 Agulló y Сobo, M., "El convento de San Diego de Alcalá", Cuadernos de Arte e Iconografía, 23 (2003), p. 12.

${ }^{6}$ Pérez SÁnchez, A. E., Historia del dibujo en España. De la Edad Media a Goya, Madrid (Cátedra), 1986, p. 224. Fechó el dibujo en 1649-50.
} 


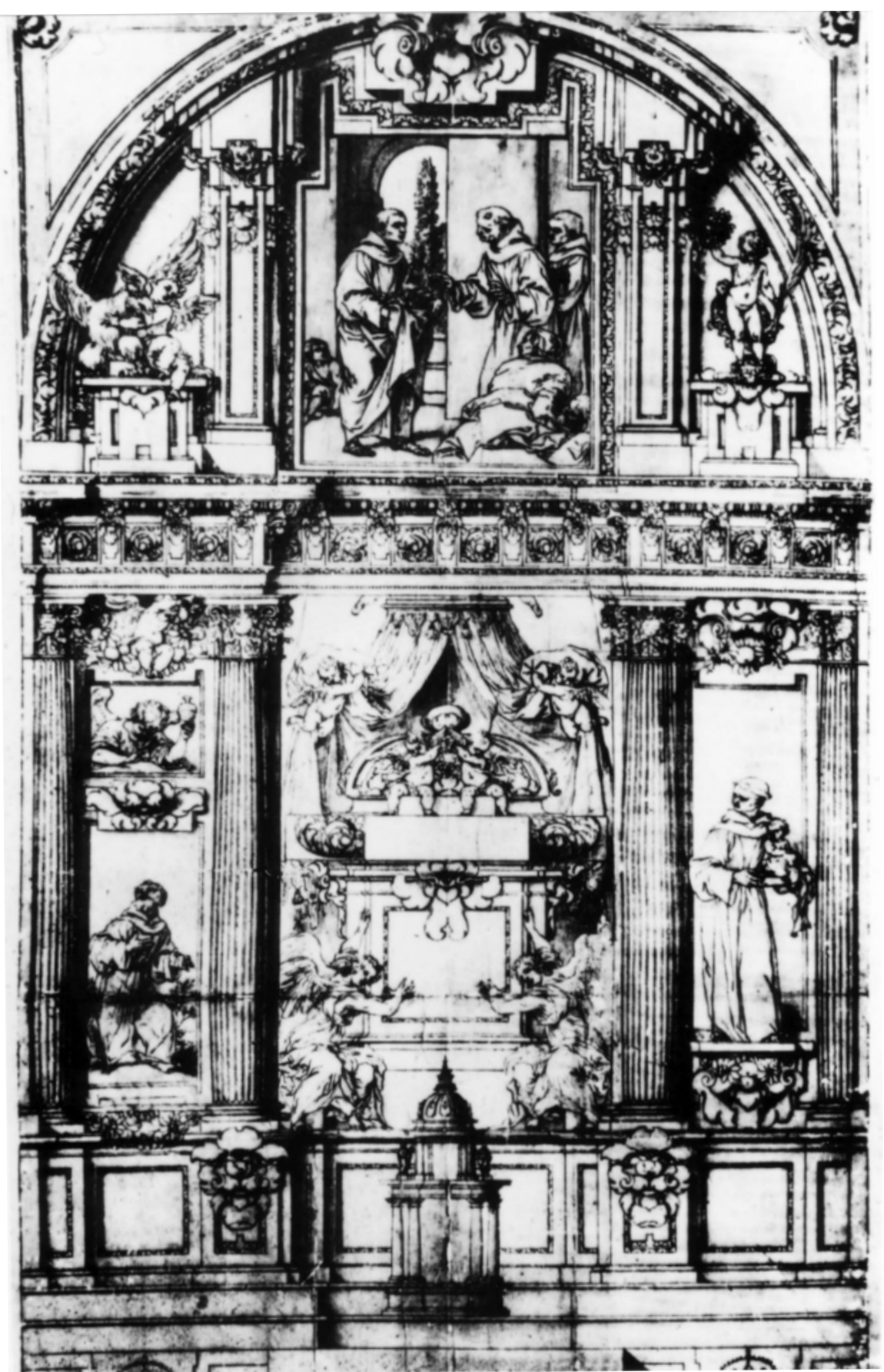

Fig. 1. Sebastián de Benavente. Traza para el retablo de la capilla de San Diego de Alcalá (colección particular, Florencia). 
Respecto a la presencia en el dibujo florentino del esquema de san Francisco y el ángel con la redoma en dos lienzos superpuestos, según el modelo usado en el retablo colateral de Santiago terminado hacia 1651/52, que Rodríguez Rebollo y Agulló invocaron como argumento a favor de la autoría de Cano, hacemos notar en primer lugar que el recurso de disponer dos pinturas separadas pero a su vez relacionadas es propio del barroco y los retablos madrileños ofrecen algunos ejemplos. En segundo término, señalaremos una diferencia iconográfica que nos parece importante. En el dibujo de San Diego, la postura de san Francisco le muestra con los brazos pegados al cuerpo, con una mano en el corazón y otra ligeramente levantada, mientras Cano representó al Santo en una postura distinta tanto en el colateral de Santiago como en el de San Diego, de rodillas con los brazos abiertos y alzados, a pesar de que se trataba de dos pasajes diferentes de su vida, el Milagro de la redoma y la Estigmatización.

Sebastián de Benavente tuvo una participación esencial en la obra del convento de Santa María de Jesús de Alcalá y en su capilla de San Diego, como lo acredita su presencia en varios contratos celebrados al menos desde 1653 hasta 1662. La primera etapa constructiva de la capilla, bajo la dirección del maestro de obras Jerónimo Lázaro, se extendió hasta septiembre de 1649 en que murió, dejando terminada la edificación propiamente dicha, aunque no su decoración. Su fallecimiento provocó la detención de las obras, pues el contrato con el albañil Juan García para el revoco del interior, de febrero de 1653, más de tres años después, hace expresa mención de que Lázaro había muerto sin terminarla; Benavente aparece en ese momento ya como testigo. El comienzo de esta segunda etapa coincide, pues, con el principio de 1653, en que Benavente aparece ligado a las obras de la iglesia del convento dirigiendo la obra de la sillería. Las dificultades económicas fueron causa de nueva detención hacia 1654 -no se hizo, por ejemplo, la labor de rejería contratada con Cialceta en diciembre de 1653-, hasta que Felipe IV realizó un importante donativo al que luego nos referiremos, que permitió dar nuevo impulso y acometer los importantes contratos de 1657 y 1658 para el solado del presbiterio, rejas, retablos, pintura del camarín y urna del Santo, además de varias piezas de plata y de madera para adornar el presbiterio, terminándose por fin la gran urna de jaspe del santo y la portada de la capilla hacia 1662 con una limosna de la reina Mariana.

Los datos por los que consideramos que Benavente fue encargado de idear y dirigir la decoración y amueblamiento de la capilla son los siguientes:

En 26 de febrero de 1653 asiste como testigo al contrato del maestro de albañilería Juan García para el revoco de las bóvedas de los coros alto y bajo de la iglesia conventual y de la capilla del Santo y decoración de sus capiteles y cornisas?.

Los ensambladores Juan de San Payo y Francisco González Bravo hicieron contrato en 3 de agosto de 1653 para realizar 102 sillas del coro del convento por 38.300 reales y Benavente asiste como testigo de conocimiento de los dos artífices al finiquito de la sillería, otorgado en 21 de mayo de $1658^{8}$. Carmen Román recoge una anotación hallada en las Claras de Alcalá sobre un préstamo de las monjas para pagar estas sillas y otras obras de la capilla que se dice había hecho Benavente9.

El contrato sobre la urna de mármol y jaspe exterior, de 12 de marzo de 1658, con los maestros marmolistas Vicente de Semería y Juan Eugenio Sombigo, indica que "todo ha de ser conforme a la traça, planta y alçado que está hecha y firmada de Sebastián de Benavente, maestro de arquitectura vecino desta villa"10.

\footnotetext{
7 Agulló, "El convento...", pp. 45-47.

8 Ibidem, p. 58. El finiquito cita el contrato de 1653 otorgado en Alcalá.

9 Román Pastor, C., Arquitectura conventual de Alcalá de Henares, Madrid, 1994, pp. 57-68. Las monjas de Santa Clara prestaron 11.000 reales a los franciscanos.

${ }^{10}$ Agulló, "El convento...", pp. 52-53.
} 
Rafael González, platero de Madrid, firma su contrato para la hechura de la urna de plata interior el 16 de marzo de 1658 y en él se obliga de la forma siguiente: "Todo lo qual a de ser y lo a de haçer y executar conforme a la traça que está hecha y firmada del dicho otorgante y del dicho padre Juan de San Francisco y de Sebastián de Benavente, maestro de arquitectura..."11.

El 29 de abril de 1658 contrata el retablo con trazas firmadas por él. De este asunto nos ocupamos luego extensamente.

Benavente se constituye fiador del dorador Clemente de Ávila en su contrato para el dorado del retablo mayor de 15 de mayo de $1658^{12}$.

Igualmente, Benavente presta su fianza al platero Domingo Ruiz de Arbulu, que contrataba con el convento el 25 de agosto de 1658 la realización de dos juegos de candeleros de seis piezas cada uno y doce relicarios ${ }^{13}$.

En 5 de julio de 1662, los maestros marmolistas Miguel y Pedro de Tapia y Miguel Sombigo concertaron la hechura de la portada del convento según la traza de Sebastián de Benavente ${ }^{14}$.

Agulló piensa que el dibujo puede ser de la primera o de la segunda estancia de Cano en Madrid. No es posible, a nuestro juicio, que la traza para el retablo se hiciese antes de 1652, porque ni siquiera se había contratado por parte del convento el revoco interior de la capilla. La limosna del rey fue lo que permitió a los franciscanos impulsar las obras a partir de los últimos meses de 1657, por lo que la traza ha de ser de estos momentos; lleva escudo real, recordando un patrocinio que no existía antes de 1655 .

La investigadora mantiene que sólo hubo una traza general del retablo, la de Cano, y que Benavente sustituyó la elegante y sobria custodia del granadino por otra más complicada en sus adornos, para la que hizo otra traza que se unió al contrato de 29 de abril de 1658. Piensa, además, que hubo tres diseños sucesivos para la urna de mármol y jaspe, primero el de Cano en el dibujo, sustituido por una traza que dio Benavente el 12 de marzo de 1658, y luego por otra de Semería en 1660 ${ }^{15}$. Las interpretaciones de Agulló, a nuestro juicio, no pueden apoyarse en los documentos que cita.

Benavente aparece como autor tanto del retablo como de la custodia nuevamente trazada: "las dos traças questán hechas y firmadas del otorgante y del dicho padre fray Juan". Sobre la traza general del retablo, anterior al contrato -correspondiente al dibujo florentino- se introducían las leves modificaciones que hemos comentado antes. La segunda traza era sólo de la custodia: "se ha tenido por más conveniente traçar una custodia en otra forma, según se a puesto y traçado en papel aparte, y que no se execute la que se hiço y puso en la traça del dicho retablo". Benavente cambia también la urna de mármol y jaspe: "La urna que muestra la traça para el cuerpo del glorioso san Diego no se a de haçer por haverse elejido otra". La urna que había trazado y entregado a los tallistas Semería y Sombigo el 12 de marzo de 1658, también firmada por Benavente, sería un desarrollo detallado de la que aparece en el dibujo florentino, pero en el contrato de 29 de abril, el maestro anuncia que se hará otra distinta. Semería no pudo ser inventor de una tercera urna, pues en la carta de pago de 1 de abril de 1660 dice que la iba haciendo según un diseño que había renovado el que se les entregó el 12 de marzo de 1658, por tanto, el segundo de Benavente, ya anunciado en el contrato, cuya fecha de entrega al tallista no se conoce. Era usual que un tracista introdujera modificaciones en sus trazas, pero no tanto en las de otros ${ }^{16}$.

${ }^{11}$ Ibidem, p. 54.

12 Ibidem, pp. 57-58.

13 Ibidem, p. 59.

${ }^{14}$ Barrio Moya, J. L., "El arquitecto Sebastián de Benavente y la desaparecida portada de la iglesia del convento de San Diego de Alcalá“, Anales Complutenses, 2 (1988), pp. 21-29.

15 Agulló, "El convento...", p. 14.

${ }^{16}$ V. contrato de 1662 para la ejecución de la portada, BARRIO MOYA, pp. 24 y 27. 
Desde una perspectiva general, no tiene sentido pensar que Cano, recién llegado de Granada, fuera llamado en los últimos meses de 1657 a trazar el retablo, desplazando al arquitecto madrileño en lo que era su mayor especialidad.

Que sepamos, Benavente fue tracista de los numerosos retablos que ejecutó ${ }^{17}$, menos en un caso, en que la traza era del maestro mayor de las obras reales Alonso Carbonel, y así se señala en el documento correspondiente; la alta posición en la Corte del marqués de la Lapilla, su comitente, justifica que pidiera una traza al maestro mayor de las obras reales, y éste se la diera y recomendara a Benavente como hombre de su confianza para llevarlo a cabo ${ }^{18}$. A la inversa, hubo algún caso en que trazó Benavente y labraron otros, como sucedió con el retablo del convento franciscano de Jesús y María cuya hechura se contrataba en Valladolid con un maestro local el mismo día que Benavente firmaba en Madrid el contrato de San Diego. El retablo vallisoletano se haría según invención de Benavente por un ensamblador de aquella ciudad, y la escritura expresa que el madrileño había hecho y firmado la traza y que todo se haría según su parecer. Cuando el tracista era diferente del artífice, el hecho solía mencionarse en la escritura y de algún modo quedaba establecida su primacía en cuanto al juicio sobre el cumplimiento de las condiciones. Así, por poner un ejemplo relativo al mismo Francisco Bervilar, que luego interviene en Alcalá, en la escritura de 24 de agosto de 1647 para el retablo de la capilla del Amparo de la parroquial de Colmenar de Oreja se menciona expresamente que lo dará "hecho y acavado en toda perfection conforme la traça y condiciones echas por el padre fray Laurencio de San Nicolás...la qual obra ará a contento y satisfacción del dicho padre fray Laurencio" "19. No hay precisiones de este tipo en el contrato del retablo de San Diego y, contrariamente, se dice que Benavente hizo y firmó las trazas tanto del retablo como de la custodia.

El contrato de 29 de abril de 1658 no dice que haya existido otro anterior con Bervilar en que se fijaran el precio y condiciones del retablo. No sería ilógico que lo hubiera habido, dada la importancia económica del encargo. Sin embargo, Benavente contrata sin constituirse en sucesor de nadie. El nombre de Francisco Bervilar sólo aparece en una cláusula poco significativa, bastante adelantadas las estipulaciones, donde se aclara que algunas piezas que había labrado antes de su muerte se entregaban a Benavente sin que tuviera que pagar nada por ellas.

Debía de hacer poco tiempo que Bervilar entendía en la obra del retablo cuando murió, ya que había hecho unas pocas piezas cuyo precio ni siquiera se considera expresamente. En el contrato de 29 de abril de 1658 hay algún dato del que puede deducirse lo que estaba hecho. El cuerpo principal, donde se abría el transparente, no estaría comenzado, puesto que se elige entonces una de las dos soluciones que ofrecía la traza para las calles laterales, precisamente la que tenía las dos pinturas de san Francisco y el ángel. Las únicas piezas hechas por Bervilar que se identifican en el texto formaban parte del pedestal: "y si para mayor adorno fuere necesario que en las cartelas que oy están hechas en el pedestal principal del retablo hacer algunos trapos o festones, se aya de hacer lo que más convenga".

${ }^{17}$ CruZ YÁbar, J. M., El arquitecto Sebastián de Benavente (h.1620-1689), Trabajo de investigación de doctorado presentado en la Facultad de Geografía e Historia de la Universidad Complutense de Madrid, junio 2004 (inédito).

18 Saltillo, Marqués De, "La capilla de Santo Domingo Soriano en la iglesia del convento de Santo Tomás", Revista de la Biblioteca, Archivo y Museo, LIV (1946); pp. 155-157; Puerta Rosell, M. F., "Aspectos artísticos de un patronazgo madrileño del siglo XVII. Don Fernando Ruiz de Contreras y la capilla de Santo Domingo en la iglesia del convento de Santo Tomás", en Actas del VII Congreso Español de Historia del Arte, Murcia, 1988, pp. 351-357.

19 Cfr., respecto al retablo vallisoletano, Pérez Villanueva, J., "Unos lienzos de Mateo Cerezo en el convento de Jesús y María de Valladolid”, Boletín del Seminario de Estudios de Arte y Arqueología, III (1934-1935), pp. 331-350; el contrato, pp. 346-350. Respecto al retablo de Bervilar, Cruz Valdovinos, J. M., "Fray Lorenzo de San Nicolás y la capilla de Nuestra Señora del Amparo en Colmenar de Oreja (Madrid)", Goya, 145 (1978), pp. 28-33. 
Por las anteriores razones deducimos el estado incipiente de la obra en el momento en que se producía la sustitución. Benavente, cuya importancia como arquitecto de retablos era muy superior a la de Bervilar y, por supuesto, a la de Cano, no hubiera aceptado seguir un diseño ajeno que le obligaba a usar nuevas plantillas y a trabajar adornos a los que no estaba habituado, con merma de sus beneficios. Si hubiera existido una traza anterior, la habría sustituido con un diseño propio.

Pensamos que Benavente, una vez hecha la traza, presentó a los franciscanos a Francisco Bervilar, un maestro de segunda fila vinculado a Alcalá, para que hiciera el retablo con su traza y bajo su supervisión y quizá su fianza. Tras su muerte, Benavente optaría por no encargar el retablo a otro, sino hacerlo él mismo en su obrador madrileño. La relación tan continuada y estrecha que existía entre Benavente y el convento se trasluce en que no se le exigen fianzas, lo que es, cuanto menos, inusual. Es rara una cláusula final relativa a la exclusión de la penalidad por los retrasos en caso de muerte del maestro. Posiblemente había existido alguna reclamación por retrasos de Bervilar y Benavente pretendía evitarlo en lo sucesivo.

Díaz del Valle, primer biógrafo de $\mathrm{Cano}^{20}$, recibiría el testimonio directo del pintor cuando volvió a Madrid para su segunda estancia, pues menciona obras menores de su producción granadina anterior a 1657 como el facistol o la traza para las lámparas de la catedral cuya fama es dudoso que hubiera llegado a la Corte por otra vía. Díaz del Valle estaba al tanto de las órdenes sagradas que iba recibiendo Cano en 1658. Sin embargo de beber de una fuente tan directa, el biógrafo le asigna un único retablo, el de Lebrija, de 1629. Como obras madrileñas de arquitectura en madera cita el arco de la Puerta de Guadalajara para la entrada de Mariana de Austria y el monumento de Jueves Santo de San Gil. Dedica grandes elogios a la pintura de San Francisco del colateral de la parroquia de Santiago de Madrid, pero no le hace tracista del retablo, y, por supuesto, nada dice del de San Diego, ni siquiera de sus pinturas para los colaterales.

Para datar el momento en que Díaz del Valle terminó de escribir su texto sobre Cano hemos de fijarnos en la siguiente frase: "estaba en esta Corte en edad de 58 años, donde se... ordenó de epístola en el de 1658 con deseo de ser sacerdote". El 14 de marzo de 1658 se había expedido cédula dándole por aprobado en las cuatro órdenes menores y el 15 aprobándole de epístola (subdiaconado). Después hubo de ordenarse de diácono y aún más tarde, de misa, lo que se habría producido antes del 24 de octubre de dicho año en que el pintor dirige al Rey un memorial pidiendo una vacante de canónigo que existía en la catedral de Granada, a la que sólo podía aspirar si era sacerdote. Díaz del Valle, por tanto, escribe sus últimas frases sobre Cano después de 15 de marzo y seguramente antes de octubre de 1658, con excepción de la anotación de 1659 de que el pintor seguía vivo.

La traza para San Diego no puede ser posterior a los últimos meses de 1657 y la personalidad del tracista sería notoria en la Corte, de modo que la explicación para el silencio de Díaz del Valle podría ser que, en marzo de 1658, Cano no tuviera aún ninguna relación con la obra complutense. Los colaterales se mencionan por primera vez en el contrato de 29 de abril de 1658 con Benavente. La llegada a Madrid de Zurbarán se produce en mayo y el contrato para la pintura del transparente en julio, y si los cuatro colaterales se encargaron al mismo tiempo, como parece lógico, lo serían en torno a junio o julio de 1658 y se terminarían algún tiempo después, quedando explicado que Díaz del Valle no mencionara las dos pinturas de Cano.

Palomino afirmó que el granadino no llegó a hacer todas las pinturas de la capilla por "extravagancias de su genio", lo que sugiere que Cano, habiendo sido llamado para el encargo, no transigió con alguna condición que le pareció inaceptable. El biógrafo no es de fiar en este punto

20 Díaz del Valle, L., Origen yllustracion del nobilísimo y real arte de la pintura... Cfr. Corpus Alonso Cano, Madrid (Ministerio de Educación, Cultura y Deporte), 2002, p. 388. 
porque sus noticias sobre San Diego no proceden de Díaz del Valle, sino que son de segunda o tercera mano, como demuestra su error sobre la participación de Bartolomé Román. Es posible que Bervilar, elegido por Benavente para hacer el retablo mayor, hubiera recomendado a Cano para los lienzos -como lo había hecho en 1645 y 1650- y que, por su muerte, el granadino perdiera a su valedor ${ }^{21}$. Pero no que hubiera alguna fricción, pues no aceptaría pintar dos colaterales si hubiera estado enemistado con Benavente.

El camarín y el dorado del retablo mayor tenían como límite de entrega el 15 de septiembre de 1658 según los respectivos contratos, lo que era indispensable para que Benavente pudiera cumplir con su obligación de darlo asentado para fin de septiembre. Pensamos que la urgencia en su terminación estaba relacionada con la fecha prevista inicialmente para la inauguración solemne de la capilla, que sería la fiesta de San Diego de Alcalá, 13 de noviembre. Se retrasó, sin embargo, hasta el 20 de mayo de 1659, festividad de San Bernardino de Siena, por causas desconocidas $^{22}$, aunque suponemos relacionadas con la falta de caudales como expresamente sabemos que ocurrió con la urna de mármoles y jaspe. El retraso se conocía ya el 25 de agosto de 1658, cuando los franciscanos contrataron con Domingo Ruiz de Arbulu los candeleros y relicarios de bronce dorado para fin de enero de 1659. Por tanto, no existe inconveniente en suponer que los colaterales se pintaron por Cano y Zurbarán entre el verano de 1658 y principios del año siguiente, precisando algo más lo dicho en el punto anterior.

Los biógrafos antiguos de Cano no mencionan ningún retablo de importancia hecho por el pintor en Madrid. El informe de Juan Gómez de Mora de 26 de agosto de 1643 acerca de las capacidades de Cano para ocupar la plaza de maestro mayor de la Catedral y el Alcázar toledanos ha sido un valioso testimonio de su habilidad como tracista, pero no aumenta su catálogo: "Alonsso Cano, pintor grande en esta facultad, traça para todo jénero de retablos y otras obras de ensamblaje y adorno con grande primor..." ${ }^{23}$. Cano había venido a Madrid cinco años antes con la fama de ser maestro de retablos; Gómez de Mora, siempre diplomático, endulzaba con este elogio su juicio desfavorable del candidato para la plaza a que aspiraba. Díaz del Valle, por su parte, afirma que: “... salió tan aventajado en la Architectura que ha dado luz a los artífices destos tiempos para la sepan onrar, como se conoce en los nuevos templos que en esta Villa de Madrid, Corte de su Majestad Católica, se han fabricado". Un par de frases ambiguas -que pueden referirse a la invención de adornos para edificios- han sido suficientes para que los historiadores trataran de descubrir esos templos madrileños que habían recibido el influjo benéfico del granadino dominador de todas las Artes. Como los datos históricos se resistían a concederle edificios, las atribuciones le dieron varios retablos.

Sin embargo de los prometedores comienzos sevillanos, la carrera de Cano como retablista se interrumpió con su venida a Madrid. No existe ninguna noticia documental o biográfica que asigne a Cano un retablo madrileño relevante que se hiciera por su traza o bajo su dirección. Llaguno ya advierte la ausencia de noticias sobre obras de arquitectura hechas por el pintor en la Corte ${ }^{24}$. Palomino añadió varias obras a la lista de Díaz del Valle, entre ellas, la noticia de su participación en San Diego pintando dos colaterales y la poco verosímil historia de que los franciscanos quisieron que fueran de su mano todas las pinturas de la capilla. Pero, sea como fuere,

${ }^{21}$ Cruz YÁbar, J. M., "Los retablos de la parroquia de Santiago de Madrid. Pedro de la Torre, Sebastián de Benavente y Alonso Cano", Anales del Instituto de Estudios Madrileños, XLV (2005), pp. 155-177.

22 Este dato se conoce por el padre Rojo (Historia del glorioso San Diego de San Nicolás de Alcalá, Madrid, 1663) citado a su vez por Román PASTOR, p. 61.

${ }^{23}$ Martín González, J. J., "Arte y artistas del siglo XVII en la Corte”, Archivo Español de Arte, XXXI (1958), pp. 125-142.

${ }^{24}$ Llaguno y Amírola, E., Noticias de los arquitectos y arquitectura de España, Madrid, 1829, Madrid (ediciones Turner) 1977, IV, pp. 36-37. 
habla sólo de pinturas. Por lo que respecta a sus retablos, únicamente consiguió incrementar la lista de Díaz del Valle con el de Santa Paula de Sevilla.

La recepción entre los autores modernos del concepto de gran arquitecto de Cano es general ${ }^{25}$ y son pocas las voces discordantes, aunque el proceso parece hallarse en fase de reversión en las últimas décadas. En el estado actual de la investigación acerca de los retablos madrileños de Cano, sólo puede dársele con seguridad el de Santa Catalina de Alejandría que estuvo situado en un pilar de la iglesia de San Miguel de los Octoes, del que se conserva el dibujo ${ }^{26}$. Es poco más que un marco decorado, con un sencillo sagrario y banco en la parte de abajo y encima un bello y poco usual copete sobre una cornisa quebrada, con una doble propuesta, que algunos consideran característica del pintor cuando es absolutamente común a las trazas de retablos o rejas. El cogollo de la derecha, rematado en cabeza angélica, recuerda lo que había hecho en el retablo para Santa Paula de Sevilla. El dibujo ha sido fechado por Cruz Valdovinos ${ }^{27}$ hacia 1648-1652 por la similitud de la postura de santa Catalina con la de la ninfa Terpsícore dibujada por Cano para la edición hecha por González de Salas de El Parnaso Español de Francisco de Quevedo.

Recientemente, Rodríguez Rebollo le ha atribuido la traza de un "retablico" que encargó un particular para colocar en un pilar de San Ginés de Madrid ${ }^{28}$. No obstante, el contrato de julio de 1645 dice que la traza estaba firmada por Francisco Bervilar ${ }^{29}$, que era el contratante, y Cano aparece en la escritura sólo como testigo. Corría por cuenta del ensamblador darlo dorado -la pintura quedaba fuera de su cargo, y sería lo que tocaba a Cano- y la responsabilidad de cualquier incumplimiento era de Bervilar. En todo caso, el ejemplar para San Ginés era de muy escasas dimensiones y empeño, con precio, incluido el dorado, de 4.500 reales, que vendría a suponer unos 3.000 para el ensamblador -casi trece veces menos de lo que cobraría Benavente por San Diego que eran 3.500 ducados, esto es, 38.500 reales sin el banco que había hecho

25 Sánchez Cantón, F. J., Dibujos españoles, Madrid, 1930; Wethey, H., Alonso Cano: pintor, escultor y arquitecto, Madrid (Alianza), 1983, pp. 93-96.

26 WeTHEY, p. 94.

27 Cruz Valdovinos, J. M., "Encargos y clientes de Alonso Cano en la corte de Felipe IV”, en Alonso Cano. La modernidad del siglo de oro español, Madrid (Junta de Andalucía-Fundación Santander Central Hispano), 2002, 73-89, en especial, 83-84.

${ }^{28}$ Rodríguez Rebollo, A., "El retablo de San José, de Alonso Cano, en la iglesia madrileña de San Ginés", Goya, 297 (2003), pp. 360-365.

${ }^{29}$ Bervilar aparece inscrito el 5 de marzo de 1640 en el libro de los oficiales del arzobispado de Toledo entre los escultores y ensambladores de Alcalá (Gutiérrez García-BraZAles, M., Artistas y artífices barrocos en el arzobispado de Toledo, Toledo (Caja de Ahorro Provincial de Toledo), 1982, pp. 52 y 70). El 18 de julio de 1645 contrataba un retablo de la Natividad para la casa profesa de los jesuitas de Madrid y en septiembre el pequeño retablo de San Ginés; el 27 de julio de 1646, Diego Velázquez otorgaba un poder a un procurador para que siguiera pleito contra el ensamblador (Agulló y CoBo, M., "El monasterio de San Plácido y su fundador el madrileño don Jerónimo de Villanueva, protonotario de Aragón”, Villa de Madrid, XII (1975), p. 42); el 24 de agosto de 1647, Bervilar se obligaba a hacer en blanco el retablo para la capilla del Amparo de la parroquial de Colmenar de Oreja según traza de fray Lorenzo de San Nicolás en 6.000 reales, mientras Juan de Solís se obligaba a dorarlo, estofarlo y pintarlo por 5.500 reales (CRUZ VALDOVINOS, "Fray Lorenzo..."). El 3 de junio de 1648 contrataba otro retablo para la capilla de San Juan Bautista del convento de Santo Domingo el Real por 650 ducados, según su propia traza, incluyendo el dorado y estofado (Agulló y CoBo, M., Documentos sobre escultores, entalladores y ensambladores de los siglos XVI al XVIII, Valladolid (Universidad de Valladolid), 1978, p. 20). Intervino en la entrada de Mariana de Austria formando compañía con Pedro, José y Juan de la Torre, Gabriel Vázquez y Antonio Jiménez Vita (Agulló y CoBo, M., "Addenda a Pedro de la Torre", Anales del Instituto de Estudios Madrileños, XXXVIII (1998), p. 179). El 21 de mayo de 1650 hizo en blanco una urna para un Cristo yacente de Juan Sánchez Barba en 2.950 reales (SAltillo, Marqués DE, "Efemérides artísticas madrileñas (16031811)", Boletín de la Sociedad Española de Excursiones, 1948, p. 20). El 12 de noviembre de 1651 recibía 465 reales en préstamo que devolvía el 7 de mayo de 1652 (Agulló, Documentos sobre escultores..., p. 20). Murió a principios de 1658, dejando hecho el banco del retablo de San Diego de Alcalá, que contrataría poco antes. 
Bervilar, precio propio de un retablo más que mediano-y unos 1.500 aproximadamente para el dorador.

Otro tanto sucede con el retablo de San Francisco, colateral de la parroquia de Santiago, pagado con dinero de la memoria de Francisco de Herrera según unas cuentas que se protocolizaron el 26 de julio de 1650 que ha dado a conocer Díaz Moreno ${ }^{30}$. Antes de esa fecha, se pagaron a Bervilar 5.000 reales por el retablo y su pintura -en realidad, el retablo en blanco, más su dorado y estofado-, y, aparte, 150 reales a Cano por el aderezo y pintura de la puerta del retablo con el Buen Pastor. El ensamblador es contratante y a Cano se le pagan sus pinturas aparte, una manera de actuar semejante a la de San Ginés. En efecto, en otras cuentas posteriores, protocolizadas el 21 de noviembre de 1653, consta que se habían pagado a Cano y Bervilar -a los que se llama pintores- 500 reales más por la obra que hicieron en este mismo retablo, que serían las dos pinturas de San Francisco y el ángel de Cano, y 100 reales al dorador Pedro Pérez de Araujo por unos retoques que hizo. Por alguna razón, el pintor entregó los lienzos después de acabado, dorado y asentado el retablo -antes de 1652 en que volvió a Granada-, pues su paga figura en estas segundas cuentas y en las primeras sólo el Buen Pastor, y los retoques del dorador pudieron estar relacionados con la tardía colocación de las pinturas.

Son dos, por tanto, las ocasiones en que Bervilar llamó a Cano a pintar en los retablos que había contratado. Pero el arquitecto utilizó en esta época también a Juan de Solís. Este hecho y que Cano cobrara aparte de Bervilar sus pinturas, tanto en Santiago como en San Ginés, hace poco probable que existiera entre ambos un contrato de compañía. Los retablos que se conocen de Bervilar son siempre pequeños, con presupuestos poco superiores a 7.000 reales o menos El retablo de San Diego, una obra de gran envergadura, se le encargaría por recomendación de Benavente y con su garantía.

Hace tiempo que se retiró la atribución a Cano de la traza de los retablos colaterales de la iglesia de la Magdalena de Getafe aceptada por Wethey sobre la base de que había hecho las pinturas $^{31}$. Cruz Valdovinos ${ }^{32}$ precisó en 1985 que el ensamblador Salvador Muñoz había otorgado carta de pago por el de Santa María de la Paz el 18 de diciembre de 1644, y que en su testamento de 7 de enero de 1645 declaraba que sólo se le debían 223 reales de resto. Tras su muerte, acontecida poco después, se contrató el segundo colateral -del Niño Jesús- con su yerno Gabriel Vázquez, lo que sucedía antes del 1 de febrero de 1645 en que el pintor Antonio Monreal daba poder a Vázquez para que le obligara como su fiador en el contrato con el cura de Getafe; este colateral sigue fielmente a su pareja, lo que prueba que la traza era de Muñoz y que Cano no participó, pues estaba en Valencia. Salvador Muñoz fue famoso retablista y tratadista de arquitectura y el clasicismo de estos retablos y su sobriedad decorativa acreditarían por sí mismos que nada tienen que ver con Cano.

30 Díaz Moreno, F., "Alonso Cano y el retablo de San Francisco en la iglesia de Santiago de Madrid", Anales de Historia del Arte, 2007 (en prensa). Agradecemos al autor que nos haya facilitado la consulta de su trabajo antes de la publicación. Los 500 reales que parece que cobró Cano por las dos pinturas hechas entre 1650 y 1652 son un precio normal para una obra que sólo llevaba una figura, sin gran variedad de colorido, más el pequeño lienzo con la cabeza de un ángel y una ampolla en una mano. Su labor en el sagrario le había valido 150 reales. Antes de conocer la documentación descubierta por Díaz Moreno propusimos -inducidos por la fecha que Ángel RodRíGUEz REBOLLO ("Una obra inédita de Alonso Cano en los fondos del Arzobispado de Madrid", en Alonso Cano y su época, Granada (Junta de Andalucía), 2002, pp. 727-734) había dado al cuadro de San Francisco de Cano para Santiago- que Benavente hubiera recibido el encargo de hacer los colaterales de la iglesia en premio a una importante baja que había realizado en el segundo cuerpo del retablo mayor que estaba encargado a Pedro de la Torre (CRUZ YÁBAR, J. M., "Los retablos..."). Esta propuesta, aunque inexacta como se ha demostrado por la documentación, no afecta a nuestra hipótesis sobre San Diego, a pesar de la coincidencia de que Bervilar trabajara en los dos retablos.

31 Wethey, p. 94.

32 Cruz Valdovinos, J. M., "Varia canesca madrileña”, Archivo Español de Arte, 231 (1985), pp. 276-286. 
El proceso de depuración del catálogo canesco continúa en el dibujo para un retablo de San Juan de Dios que se conserva en el Prado, puesto a nombre del granadino desde hace más de setenta años. Ha sido restituido a Juan Gómez de Mora por Marías, que observó el parecido de la traza con la descripción del retablo que se contrataba en 1633 para Antón Martín ${ }^{33}$; este retablo estaba terminado en $1635^{34}$. La talla de la Virgen dibujada en la hornacina central sería la imagen de Nuestra Señora del Amor de Dios, que era la advocación del hospital madrileño.

Todo lo dicho en este punto ha de ponerse en relación con lo que parece un hecho contrastado, y es que Cano no pudo, por diversas razones, actuar en Madrid como contratista de retablos. En el momento en que llegó a la Corte, existía en ella un buen puñado de maestros consagrados -potentes económicamente y con probada experiencia y sabiduría arquitectónica- a quienes llegaban los grandes encargos. Cano no tenía capital ni medios para comprometerse en obras de alto precio. No hay sino observar la frecuencia con que aparecen en los documentos del momento como tracistas o contratistas los nombres de Juan Gómez de Mora, Alonso Carbonel, el hermano Bautista, fray Lorenzo de San Nicolás, Pedro y José de la Torre, Juan Bautista Garrido, Bernabé Cordero o Salvador Muñoz, como más destacados -amén de una docena más de maestros de segunda fila como Bervilar-y, a partir de 1653, Sebastián de Benavente, frente al silencio que guardan sobre la actividad de Cano en esta vertiente artística. No cabe dudar del dominio del dibujo por parte de estos artífices, y, así las cosas, parece sensato pensar que sean los autores de la mayoría de las trazas de retablos, e incluso de sus fragmentos o de sus elementos decorativos que circulan hoy a nombre del pintor granadino.

Para caracterizar el estilo de los retablos de Cano apenas disponemos de los dos ejemplares tempranos andaluces y del citado marco-retablo para adosar a un pilar de San Miguel de los Octoes. Los sevillanos resultan algo retrasados si se comparan con lo que se estaba haciendo en Madrid en ese momento ${ }^{35}$.

Se ha hecho clásico invocar el texto de Lázaro Díaz del Valle sobre las innovaciones contenidas en el arco de la Puerta de Guadalajara de 1649: "Obra de tan nuebo usar de los miembros y proporciones de la Architectura que admiró a todos los demás artífices porque se apartó de la manera que hasta estos tiempos habían seguido los artífices de la Antigüedad”. Sin embargo, no parece haberse analizado desde el punto de vista arquitectónico la descripción contenida en un manuscrito sobre la entrada real, redactado seguramente por don Lorenzo Ramírez de Prado, inspirador del programa iconográfico de las decoraciones ${ }^{36}$. Se describe como un arco de un solo vano en forma de medio punto con una bóveda adornada de cogollos con fajeados de jaspe de colores, un resplandor entre nubes y un escudo real colgante; en las fachadas, dos columnas de orden compuesto a cada lado "con alguna estravagancia"; sobre sus capiteles apoyaba una cornisa arquitrabada; en las esquinas había cuatro murallones cuadrados de un metro y medio de lado y de altura idéntica al vano del arco, que remataban en mascarones cuya frente eran tarjetas con inscripciones alusivas a otras cuatro estatuas superpuestas en las esquinas que simbolizaban flores asimiladas a los contrayentes. Por encima de ellas y del arco de la puerta principal había una cornisa que el cronista califica "de nueva disposición", con modillones y en su intermedio racimos de frutas pendientes, y en el segundo cuerpo, sobre una plataforma alta sostenida con

\footnotetext{
33 Marías, F., "Alonso Cano y la columna salomónica", en Figuras e imágenes del Barroco, Madrid (Fundación Argentaria-Visor), 1999, p. 291.

34 Agulló y CoBo, M., Documentos sobre escultores..., p. 61.

35 Por ejemplo, el de Antón Martín de 1633 de Gómez de Mora, o el del hospital madrileño del Buen Suceso, algo anterior a 1635 y Pinto, de 1637, de Pedro de la Torre.

${ }^{36}$ El texto del manuscrito en la parte que interesa aparece transcrito en SUÁREZ QUEVEDO, D., "Alonso Cano y el arte efímero. Homenaje al artista granadino en el cuarto centenario de su nacimiento", Anales de Historia del Arte, 11 (2001), pp. 231-267.
} 
cuatro cartelones y otros ornamentos arquitectónicos y festones, un árbol de dos troncos, uno de vid y otro de laurel, que significaban la unión de las dos ramas de la casa de Austria para producir frutos de coronas. Toda la construcción jugaba con cromatismos de verde y blanco con toques rojizos, imitando el jaspeado.

La originalidad del arco de Cano deriva tanto de los elementos estructurales como de los decorativos. Son novedad, al menos respecto a los monumentos efímeros españoles del momento, los murallones rematados en mascarones y la plataforma superior sostenida por cartelas y coronada por un árbol. La decoración algo extravagante de las columnas y los modillones que sostenían la cornisa alternando con florones colgantes resultaron también novedosos al cronista. Algunos elementos recuerdan al arco de la Ceca que Rubens había diseñado en 1635 para la entrada en Amberes del cardenal infante don Fernando, el cual fue grabado por Theodor van Thulden en 1641 para una publicación que, sin duda, había llegado a Madrid antes de $1649^{37}$. Este arco inspiraría a Herrera el Mozo para la construcción efímera que hizo treinta años después en el mismo lugar en la entrada de María Luisa de Orleáns ${ }^{38}$. Hay al menos dos aspectos en que la invención de Cano sigue el modelo flamenco: las esquinas achaflanadas de Amberes con aparejo de grandes sillares y hornacinas, de aspecto algo manierista, se transforman en unos refuerzos amurallados en las esquinas del arco madrileño, y las tarjetas con escudos que coronaban los sillares de Rubens son en Madrid mascarones con leyendas. En ambos arcos se produce la fractura estructural del primer cuerpo respecto al segundo: en Amberes es una montaña que corona la arquitectura y en Madrid una plataforma inconexa sostenida por cartelas que daría a la construcción un aspecto de arqueta de bodas. La ruptura con la forma tradicional de los arcos de inspiración romana era total tanto en uno como en otro. Aún más clara es la emulación literal en el remate, pues en ambos fue un árbol. Cano había aprovechado las sugerencias del flamenco transformándolas: "Hagan ellos otro tanto porque yo se lo perdono"39. La imaginación desbordante del arco de Rubens inspiró estos atrevimientos de Cano, y ambas construcciones crean la impresión de gran originalidad por la cantidad de fantasías que incorporan.

La tendencia de Alonso Cano a producir estructuras originales y poco sumisas a la tradición clásica ha sido subrayada ya por algún autor ${ }^{40}$. Los retablos sevillanos acusan la tendencia y la confirma el arco de 1649, por lo que estamos convencidos de que, en las escasas oportunidades que tuvo de practicar sus habilidades arquitectónicas, Cano se movió siempre al margen de los patrones al uso. Sus trazas debían de resultar peculiares, raras, tal y como observaron sus contemporáneos respecto al monumento de Semana Santa de San Gil o al arco de la Puerta de Guadalajara, e incluso se puede apreciar en su dibujo para el retablo de Santa Catalina, a pesar de la escasa envergadura de la obra. Todos ellos nos apartan del esquema regular y mesurado del retablo de San Diego de Alcalá.

Por el contrario, la traza del dibujo florentino coincide con el estilo de Sebastián de Benavente. Se trata de un artífice de la generación siguiente a Cano, afincado en Madrid por lo menos desde 1651 -podría ser madrileño- y que recibe encargos de retablos de la mayor importancia desde 1653, frecuentemente relacionados con los franciscanos. Varios ejemplares de Benavente que han llegado a nuestros días ofrecen gran similitud con el dibujado para San Diego, como el de Jesús y María de Valladolid (fig. 2) de 1658, y en especial el de la capilla de San José de la parroquial de Aldeavieja (fig. 3), poco posterior. Sitúa en el cuerpo central cuatro columnas

\footnotetext{
37 Gevaerts, J. C., Pompa introitus honoris Sereníssimo Principis Ferdinandi Austriaci..., Amberes, 1641-1643.

38 ZAPATA, T., La entrada en la Corte de Maria Luisa de Orleáns, Madrid (Fundación para el Apoyo a la Historia del Arte Hispánico), 2000, p. 158.

39 Palomino, p. 988.

40 Rodríguez G. De Ceballos, A., "Alonso Cano y el retablo”, en Figuras e imágenes del Barroco, Madrid (Fundación Argentaria-Visor), 1999, p. 263.
} 
de orden corintio poco salientes respecto al plano del retablo, grandes cogollos o guirnaldas en emplazamientos delimitados por listones sobre las pinturas o nichos, separa los cuerpos mediante un entablamento con modillones y cogollos carnosos en el friso y el ático es un gran arco de medio punto moldurado con un entredós de hojas superpuestas, machones con racimos a los lados de la pintura central y una gran tarjeta en el remate. Frente a otros maestros del momento, se observa una simplificación de los elementos arquitectónicos; elude la complejidad de la estructura quebrada con cuerpos que se adelantan y retrasan y tiende a la planitud, compensada con una ornamentación abundante pero adaptada al marco arquitectónico. El retablo de Aldeavieja, además, tiene adornos tallados y esculpidos de gran parecido con los del dibujo florentino: en la parte superior, los santos de las enjutas tienen la misma postura que los ángeles que muestran la urna de San Diego, el ángel niño del águila en el retablo de Alcalá es semejante al abulense que está en el intercolumnio del evangelio y el de la enjuta de la epístola en San Diego con una palma es idéntico a los que están en el banco de Aldeavieja. Las custodias de ambos son muy parecidas, aunque en Aldeavieja está presente una innovación que adoptará el arquitecto en las décadas siguientes, la unión de los dos cuerpos mediante el arco de la puerta del sagrario que

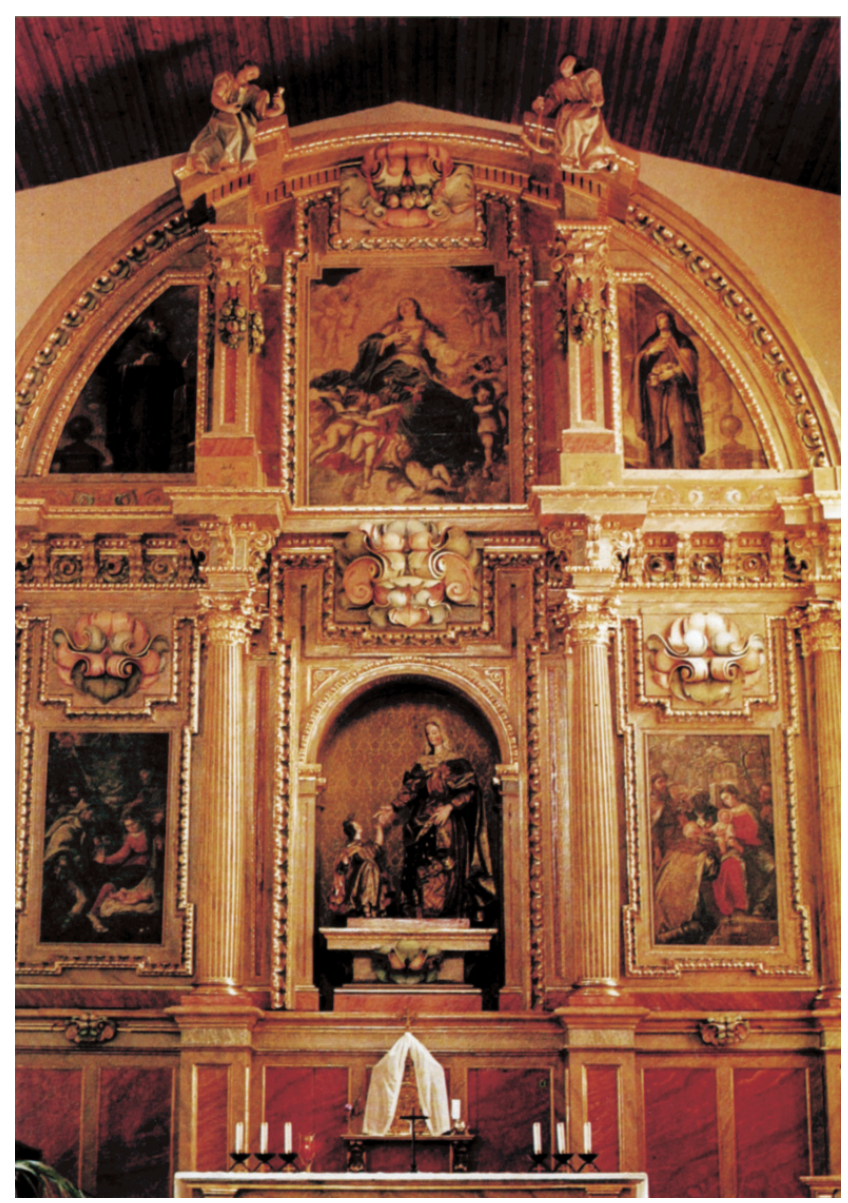

Fig. 2. Sebastián de Benavente. Retablo mayor del convento de Jesús y María de Valladolid. 


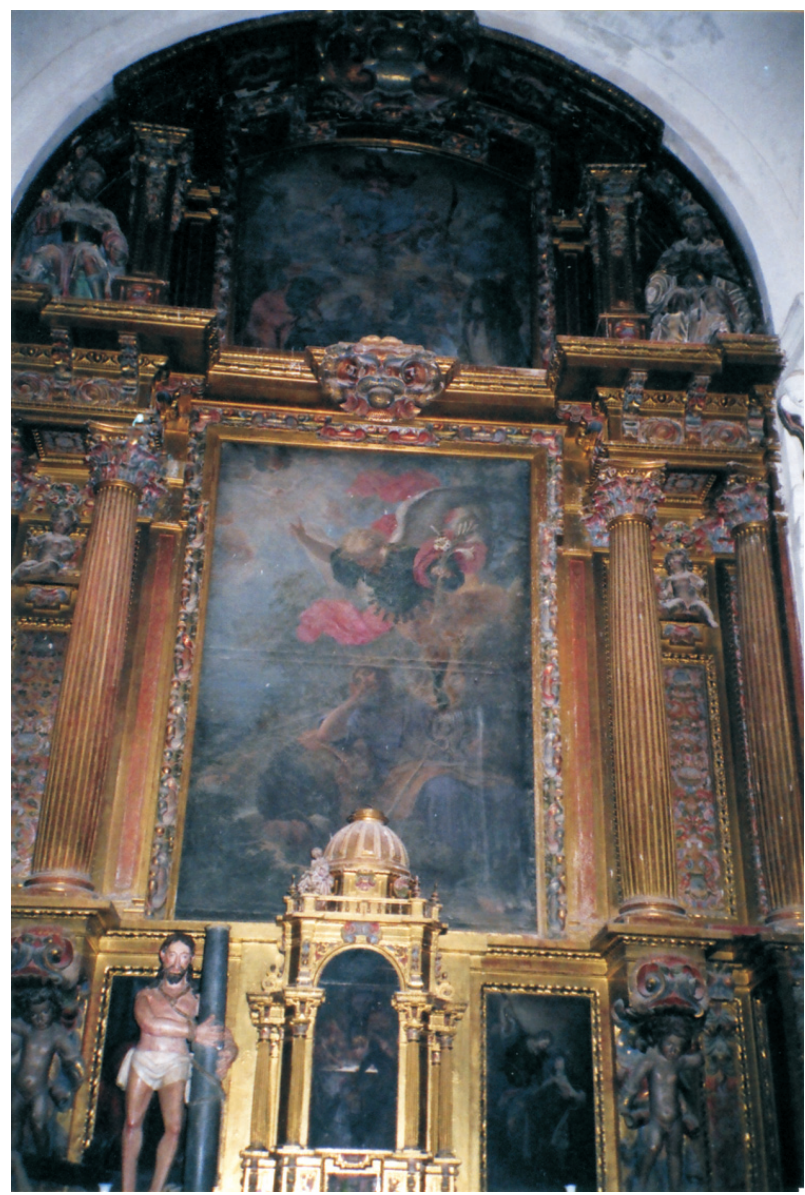

Fig. 3. Sebastián de Benavente. Retablo de la Capilla de San José. Iglesia parroquial de Aldeavieja (Ávila).

rompe el entablamento. Es posible que en Alcalá introdujera ya esta novedad en la modificación de la custodia que presentó en el contrato de 29 de abril de 1658.

La cuestión del patrocinio de las obras tiene también trascendencia en la forma en que se eligió a los artífices. La capilla fue de patronazgo real desde su construcción en el siglo $\mathrm{XV}^{41}$ y los franciscanos deseaban engrandecerla, pero sólo lo hicieron merced a la promesa de un gran donativo de doña Ana de Llamas el 14 de mayo de 1640. Con esta y otras limosnas se empezó la obra, pero la quiebra de esta señora y la muerte en 1649 del maestro Jerónimo Lázaro Goiti paralizaron la ampliación. Cuatro años después se reanudaron las obras aunque sin grandes recursos, porque sólo debió de realizarse el revoco interior que hizo Juan García y poco después, el 24 de noviembre de 1653, la pintura de la media naranja y pechinas por Gregorio de Utande. Ninguno de estos contratos menciona al rey como patrono ni a la presencia de sus armas, en especial, en la reja que se contrató con Domingo de Cialceta y que luego no se hizo.

${ }^{41}$ Noticia procedente del padre Rojo, citada por RoMÁn PASTOR, p. 60. 
En 1655 se tiene por primera vez constancia de que Felipe IV patrocinaba la obra, según revelan dos documentos que hemos hallado ${ }^{42}$. El 14 de enero de 1656, el padre fray Juan de San Francisco, administrador de las limosnas de la capilla, declaraba que había recibido una libranza de 3.807.000 maravedís -equivalentes a 10.180 ducados- que el Rey había mandado dar para la obra de San Diego y que se había de cobrar del arrendador de la renta de la lana en la mejora de la reducción de la moneda de vellón del año 1655. Del documento se deduce que había percibido ya 2.454.000 maravedís, porque consentía en que 1.353.000 maravedís restantes fueran cobrados antes por los franciscanos de los Santos Lugares -que serían acreedores también del mismo arrendador- siempre que quedara a salvo la integridad del crédito de San Diego. El patrocinio real se confirma con la aparición de José de Villarreal dando pareceres y de don Antonio de Contreras como superintendente en el contrato con el cantero Pérez de Irias, celebrado el 31 de octubre de 1657. En el contrato de Mateo Báez de 1658 para la reja de la capilla se habla ya de que el escudo llevaría las armas reales, lo mismo que el retablo, la urna de plata y las cuatro grandes lámparas que se hicieron.

Las obras que se realizaron entre 1657 y 1662 costaron más de 15.000 ducados, por lo que la importante limosna real no debió de ser suficiente y se añadirían algunas otras de particulares. Nuevas dificultades financieras surgieron algo antes de inaugurarse la capilla el 20 de mayo de 1659. La urna de jaspe faltó ese día y el 19 de octubre de 1661, fray Juan de San Francisco suscribe un documento como "procurador del convento de San Diego de Alcalá por cuya cuenta y riesgo corren las obras de la capilla de San Diego, urna de jaspe y portada de la iglesia"43, aceptando la cesión por un franciscano de una cédula del Rey despachada en 12 de mayo de 1659 con 26.662 reales de cuantía, de los que había cobrado sólo 5.500 reales, para que aplicara el resto a la obra de San Diego. Poco posterior fue el gesto de generosidad de Mariana de Austria, que costeó la portada y designó como supervisor de la obra a Francisco de Iriarte, tal como indica el contrato de 5 de junio de 1662 de los maestros con el convento. La portada costó algo más de 100.000 reales.

En correspondencia con el patrocinio real, algunos artífices pertenecían al círculo de la Corte. Pero no en la forma que defiende Agulló, según la cual, la feliz circunstancia de que la capilla se ornase con cuatro lienzos salidos del pincel de Cano y Zurbarán pudo deberse a la intervención de Velázquez ${ }^{44}$. Dudamos de que sus oficios de aposentador del rey y ayuda de superintendente de las obras del Alcázar le dieran competencias en obras reales ajenas al Palacio ${ }^{45}$. El título de maestro mayor de las obras reales correspondía entonces a Alonso Carbonel, que había escogido a Benavente poco antes para hacer por sus trazas el retablo del marqués de la Lapilla, por lo que, si hubo alguna influencia de un artífice real en la elección de los artífices, sería de Carbonel.

En nuestra opinión, los artífices fueron seleccionados de modo diferente según las etapas. En la primera, entre 1653 y 1655 , se busca artífices residentes o vinculados a Alcalá, como Utande -vecino de Alcalá y activo allí según la anécdota de Palomino ${ }^{46}$ - y Cialceta o los dos maestros ya citados de la sillería de la iglesia elegidos por Benavente, cuyo finiquito indica tal vecindad. Incluso un artífice que aparece en la segunda etapa, Francisco Bervilar, tuvo también algún tipo de vínculo con la ciudad del Henares y quizá fue elegido por ello para hacer el retablo. A partir de 1657 los artífices tienen ya una clara relación con Benavente, director de la decoración, o

42 A. H. P. M., escr. Juan Luis del Águila, prot. 7384, f. 379 y 382-382 v.

43 Ibidem, prot. 7385, f. 417-420 v.

${ }^{44}$ Agulló, "El convento...", p. 16.

45 Cruz Valdovinos, J. M., "Incarichi e premi che Velázquez ricevette da Filippo IV”, en Velázquez, Roma (Fondazione Memmo, Electa), 2001, pp. 97-119. Los nombres de sus oficios fueron sucesivamente de asistente a la superintendencia de las obras particulares, veedor y contador de la pieza ochavada del Alcázar y aposentador del rey.

46 Palomino, p. 1026. 
con las obras reales. Entre los primeros hay que citar a Van de Pere y el estofador Brustín, que repetirían en Escalona, o el dorador Clemente de Ávila. Tanto Bervilar como Van de Pere, o los marmolistas Juan Sombigo y Vicente Semería, Brustín y Clemente de Ávila eran artífices dispuestos a trasladarse a Alcalá para realizar sus respectivos trabajos y sus precios no serían muy elevados, puesto que, o eran muy jóvenes, o de segunda fila. Los artífices relacionados con círculos reales que aparecen en la obra a partir de 1658 son Mateo Báez, cerrajero del rey, el portaventanero Alberto Esculte se hallaba trabajando en El Escorial, Juan García Barruelos, maestro de emplomar y empizarrar las obras reales ${ }^{47}$ y Rafael González que llegó a ser platero real. Cano y Zurbarán también habían trabajado para el Buen Retiro, pero hacía tiempo que no trabajaban para el rey.

Benavente poseía, según el inventario hecho tras su fallecimiento, sendas copias de Cano del Descendimiento y de Cristo a la columna, además de un original de San Félix de Zurbarán, valorados en precios muy altos. Agulló piensa que pudieron ser regalos de sus autores a Benavente por su contacto con ellos durante la hechura del retablo de San Diego, lo cual contradice su hipótesis de una sustitución poco amistosa de Cano por Benavente en la traza del retablo. En cierto modo, se acerca a nuestra postura cuando expresa que la extensa colección de pintura del maestro arquitecto es señal de que “... por su trabajo, tuvo que estar en contacto con los más prestigiosos pintores de su tiempo que completaban con sus obras las trazas del retablista"48. Cano y Zurbarán eran dos espléndidos pintores cuyos precios no eran excesivos y Benavente se sirvió de ellos en esta ocasión de la misma manera que lo haría a lo largo de su vida con muchos otros igualmente insignes, como Pereda o Herrera el Mozo por no mencionar sino a dos destacadísimos artífices cuya calidad no es menor que la de aquéllos.

Fecha de recepción: 30-VI-2006

Fecha de aceptación: 20-XII-2006

\footnotetext{
${ }^{47}$ Se obliga a emplomar la media naranja de la capilla el día 3 de abril de 1662 y a terminarla antes de fin de junio de ese mismo año (A. H. P. M., escr. Juan Luis del Águila, prot. 7385, f. 519-520). Se le pagó a tasación, dándole 10.000 reales a cuenta en diferentes plazos.

48 AGulló, "El convento...", p. 34.
} 